Плетнёв С. А., Шаломов В. И.

S. A. Pletnev, V. I. Shalomov

ОБЗОР РАБОТ ПО СОВЕРШЕНСТВОВАНИЮ МОЩНЫХ ПАРОВЫХ ТУРБИН НА СВЕРХКРИТИЧЕСКИЕ ПАРАМЕТРЫ ПАРА

\title{
THE REVIEW WORKS TO IMPROVE HIGH-POWER STEAM TURBINES FOR SUPERCRITICAL STEAM PARAMETERS
}

Плетнёв Семён Александрович - студент факультета энергетики, транспорта и морских технологий Комсомольского-на-Амуре государственного университета (Россия, Комсомольск-на-Амуре); 681013, Хабаровский край, г. Комсомольск-на-Амуре, пр. Ленина, 27. E-mail: sema_0104@mail.ru.

Mr. Semen A. Pletnev - a student, Faculty of energy, transport and marine technologies, Komsomolsk-on-Amur State University (Russia, Komsomolsk-on-Amur); 681013, Khabarovsk territory, Komsomolsk-on-Amur, 27 Lenin str. E-mail: sema_0104@mail.ru.

Шаломов Вячеслав Иванович - кандидат технических наук, доцент, доцент кафедры тепловых энергетических установок Комсомольского-на-Амуре государственного университета (Россия, Комсомольск-наАмуре); 681013, Хабаровский край, г. Комсомольск-на-Амуре, пр. Ленина, 27. E-mail: shalomov2012@yandex.ru.

Mr. Vyacheslav I. Shalomov - PhD in Engineering, Associate Professor, Thermal power plants Department, Komsomolsk-on-Amur State University (Russia, Komsomolsk-on-Amur); 681013, Khabarovsk territory, Komsomolsk-on-Amur, 27 Lenin str. E-mail: shalomov2012@yandex.ru.

Аннотация. В статье представлен обзор работ по совершенствованию мощных паровых турбин на сверхкритические начальные параметры пара. Приведены разработанные конструктивные решения по основному оборудованию угольных энергоблоков на сверхвысокие начальные параметры пара. Даны описания конструктивных особенностей конденсационных турбин на суперсверхкритические начальные параметры пара и теплофикационных паровых турбин большой мощности на сверхкритические параметры с увеличенными отборами на теплофикацию.

Summary. The overview of works on the improvement of powerful steam turbines for supercritical initial steam parameters is presented. The developed design solutions for the main equipment of coal-fired power units at ultrahigh initial steam parameters are given. The description of the design features of condensation turbines for supersupercritical initial steam parameters and high-power steam turbines of high power for supercritical parameters with increased selections for heating was made.

Ключевые слова: энергоблок, паровая турбина, сверхкритические начальные параметры пара, экономичность, надёжность.

Key words: power unit, steam turbine, supercritical initial steam parameters, efficiency, reliability.

УДК 621.311

Наиболее высокими параметрами в массовом производстве и в эксплуатации обладают турбины на сверхкритические значения 24 МПа и $540 \ldots 560{ }^{\circ} \mathrm{C}$. Важнейшей задачей является освоение новой ступени параметров: начального давления 28...32 МПа, температуры свежего пара и температуры пара промежуточного перегрева, равной $580 \ldots 620^{\circ} \mathrm{C}$. Такие величины параметров принято называть суперкритическими.

Энергоблоки нового поколения предполагается устанавливать на конденсационных электростанциях (КЭС), котлы которых работают на каменных и бурых углях. Коэффициент полезного действия (КПД) энергоблоков, предназначенных для замещения оборудования, выработавшего свои парковый и индивидуальный ресурсы, должен составлять $42 \ldots 46$ \%, а энергоблоков новых КЭС $-45 \ldots 47 \%$. 
Плетнёв С. А., Шаломов В. И.

ОБЗОР РАБОТ ПО СОВЕРШЕНСТВОВАНИЮ МОЩНЫХ ПАРОВЫХ ТУРБИН НА СВЕРХКРИТИЧЕСКИЕ ПАРАМЕТРЫ ПАРА

Цели обзора: 1) выявление основных направлений по развитию и совершенствованию паровых турбин, работающих на сверхвысоких параметрах пара; 2) формирование представления об особенностях перспективных турбин мощных энергетических блоков.

В источнике [3] авторами приведены результаты расчётных исследований как термодинамической, так и экономической составляющих эффекта от повышения начальных параметров пара до сверхвысоких значений для теплофикационных энергоблоков. В качестве базового варианта была принята тепловая схема турбоустановки с паровой турбиной Т-250/300-23,5.

В исследованиях рассматривались диапазоны начального давления $P_{0}=23,5 \ldots 30$ МПа, температуры $t_{0}=540 \ldots 600{ }^{\circ} \mathrm{C}$ и давления пара после однократного промежуточного перегрева $P_{\text {п.п }}=3,6 \ldots 4,5$ МПа. В расчётах термодинамической эффективности оценивалась степень влияния роста параметров пара на мощность и уровень электрического КПД энергоблока с теплофикационной турбиной.

В экономической части расчётов определялись показатели коммерческой эффективности инвестиций в соответствующие проекты, объёмы общих инвестиционных и производственных издержек.

Результаты расчётов позволили оценить оптимальный уровень сверхвысоких значений начальных параметров пара для теплофикационного энергоблока с паровой турбиной Т-280/335-26,1. Наилучшие показатели коммерческой эффективности достигаются для варианта с параметрами свежего пара и в промежуточном перегревателе $P_{0}=26,1 \mathrm{MПа}, P_{\text {п.п }}=4,035 \mathrm{MПа}$, $t_{0} / t_{\text {п.п }}=575 / 575{ }^{\circ} \mathrm{C}$. В этом случае получены значения КПД брутто $-42,56 \%$, КПД нетто $-40,96 \%$, номинальной мощности в конденсационном режиме эксплуатации - 334 МВт, а в теплофикационном при $Q_{\mathrm{T}}=1381,6$ ГДж/ч (330 Гкал/ч) - 279,1 МВт. Использование более высоких параметров пара приводит к существенному росту стоимости проектов.

В статье показано, что при модернизации энергоблоков с турбинами Т-250/300-23,5 целесообразно восстановление изначальных проектных значений температур свежего пара и после промежуточного перегрева $t_{0} / t_{\text {п.п }}=565 / 560{ }^{\circ} \mathrm{C}$.

В научной работе [7] представлены итоговые данные разработки угольного энергоблока на суперкритические параметры (СКП) пара. В публикации сделан вывод о том, что можно не только достичь высоких показателей по экономичности и надёжности нового энергоблока, но и решить много проблем, связанных с эффективным сжиганием твёрдого топлива без превышения перспективных норм по ограничению выбросов вредных веществ в атмосферу. Рассмотрены технологические методы подавления оксидов азота $\mathrm{NO}_{\mathrm{x}}$, способные обеспечить их допустимую эмиссию. Авторами представлен обзор состояния разработок современных мощных пылеугольных энергоблоков на суперсверхкритические (ССКП) и ультрасверхкритические параметры (УСКП) пара. Увеличение КПД нетто энергоблока достигается в результате оптимизации тепловой схемы, совершенствования основного и вспомогательного оборудования и, главное, повышения параметров пара перед турбиной. Благодаря повышению КПД, сокращаются выбросы вредных веществ в атмосферу, в том числе парникового газа $\mathrm{CO}_{2}$. На сегодняшний день в мировой энергетике уровень параметров пара за котлом составляет $P_{0}=30 \mathrm{MПа}, t_{0}=610 \ldots 620^{\circ} \mathrm{C}$, а КПД на таких блоках достигает 47 \%. Энергоблоки ССКП работают в Германии, Дании, Японии, Китае, Корее, ведутся проектные разработки в России. В настоящее время в ЕС в рамках программы ThermieAD700 прорабатываются проекты создания энергоблока на ультрасверхкритические параметры пара $\left(P_{0}=\right.$ $\left.35 \mathrm{MПа,} t_{0} / t_{\text {п.п }}=700 / 720^{\circ} \mathrm{C}\right)$ с КПД около $50 \%$.

В США, Японии и Китае тоже приступили к исследованиям в этом направлении. Разработка технических решений начата и в России (Всероссийский теплотехнический институт, Московский энергетический институт). Заявленный уровень параметров пара требует применения новых материалов - сплавов на никелевой основе. Учитывая высокую стоимость никелевых сплавов, отсутствие в России технологии их производства и изготовления изделий из них для паровых установок, в качестве первого этапа освоения УСКП следует рассматривать создание энергоблоков на параметры пара $P_{0}=32 \mathrm{MПа}, t_{0} / t_{\text {п.п }}=650 / 650{ }^{\circ} \mathrm{C}$, практически не требующих дорогостоящих сплавов. Для разработки и сооружения головных энергоблоков ССКП и УСКП необходимы сов- 


\section{Учёные записки}

Комсомольского-на-Амуре государственного технического университета

местные усилия правительства, энергетиков и металлургов, научных организаций и производителей оборудования.

В материалах [9] Всероссийского технологического института рассказывается о проведении комплекса исследований, в котором рассматриваются особенности поэтапного совершенствования системы регенеративного подогрева питательной воды на отечественных турбоустановках сверхкритического давления (СКД). Этапы характеризуются применением в ТУ смешивающих подогревателей низкого давления (СПНД), бездеаэраторной схемы и двухступенчатых питательных насосов. В работе рассмотрены принципиальная тепловая и пусковая бездеаэраторные схемы, обозначены их преимущества перед деаэраторной. Анализ результатов исследования показал, что увеличение КПД достигнуто благодаря повышению параметров пара до 25 МПа и $575 / 595$ ' (примерно на 2 \%), повышению температуры питательной воды до 300 ㄷ (на 0,7 \%), снижению давления в конденсаторе в результате совершенствования конструкции и поддержания его в чистоте (на 0,7 \%), использованию тепла дымовых газов (на 0,6 \%), совершенствованию турбины, вспомогательного оборудования и тепловой схемы (на 2,4 \%). Применение двухподъёмной бездеаэраторной тепловой схемы обеспечивает дополнительное повышение экономичности энергоблока и практически исключает работу с отключёнными подогревателями высокого давления (ПВД). Безусловно, использование такой тепловой схемы целесообразно при сооружении энергоблоков с суперкритическими параметрами свежего пара. При разработке проектов модернизации или сооружения новых энергоблоков следует оптимизировать трассы и сортамент паропроводов свежего пара, системы промперегрева и отборных паропроводов турбин исходя из экономически оправданного снижения потерь давления в них.

В статье [2] опубликованы результаты расчёта режимов нормальной и ухудшенной теплоотдачи при турбулентном течении диоксида углерода в круглой трубе при сверхкритическом давлении. Проведено сравнение с опытными данными по температуре стенки, гидравлическому сопротивлению трения, полученными в условиях малого влияния термогравитации. Дано объяснение особенностей конвективного теплообмена в области сверхкритических давлений.

В трудах [4] научного объединения имени И. И. Ползунова приведено описание конструктивных особенностей конденсационных турбин на суперсверхкритические параметры пара и теплофикационных турбин большой мощности на сверх- и докритические параметры с увеличенными отборами на теплофикацию. Для обеспечения высоких показателей эффективности и надёжности турбин ССКП предлагается применение принудительного охлаждения головных высокотемпературных термонапряжённых участков роторов высокого и среднего давления, реактивного облопачивания ЦВД (цилиндр высокого давления) и, по крайней мере, первых ступеней цилиндра среднего давления (ЦСД), двустенного корпуса ЦВД с узкими фланцами горизонтальных разъёмов. При введении охлаждения температура головной части ротора понижается до $480 \ldots 490{ }^{\circ} \mathrm{C}$, что позволяет использовать для изготовления роторов сталь 25Х1М1ФА.

Авторы утверждают, что увеличенное до 7 МПа разделительное давление (давление промежуточного перегрева пара) обеспечивает повышение тепловой экономичности энергоблока и позволяет не только выполнить ЦВД с жёстким ротором и без отборов пара из проточной части, но и уменьшить размеры тракта промежуточного перегрева.

Для обеспечения высокой экономичности энергоблока турбина имеет развитую систему регенеративного подогрева питательной воды. Первый отбор осуществляется из выхлопа ЦВД, последующие 5 и 3 - из проточных частей ЦСД и ЦНД соответственно. Температура питательной воды при этом достигает $295^{\circ} \mathrm{C}$.

В качестве примера авторы приводят разработку трёхцилиндровой турбины К-660-29,4 с перспективным ЦНД, длина рабочих лопаток последней ступени которой составляет 1320 мм; КПД цилиндров такой турбины составляют 92,1, 93,8 и 89 \%, а энергоблока в целом (брутто) 46,2 \% (КПД ТУ и котла 49,9 и 92,9 \% соответственно, давление в конденсаторе 5 кПа). Значение удельного расхода тепла у турбины К-660-29,4 на 9 \% меньше значения удельного расхода тепла у турбины К-300-23,5. 
Плетнёв С. А., Шаломов В. И.

ОБЗОР РАБОТ ПО СОВЕРШЕНСТВОВАНИЮ МОЩНЫХ ПАРОВЫХ ТУРБИН НА СВЕРХКРИТИЧЕСКИЕ ПАРАМЕТРЫ ПАРА

При разработках теплофикационных турбин нового поколения на параметры пара $12,8 \ldots 23,5$ МПа, $565 \ldots 600{ }^{\circ} \mathrm{C}$ с отборами на теплофикацию, увеличенными не менее чем на $12 \%$, рассматривались турбины типа Т-330/400-23,5 и Т-200/250-12,8, замещающие турбины T-250/300-23,5 и Т-180/210-12,8. Для них предлагается перенос верхнего отопительного отбора (или значительной его части) в приводную турбину питательного насоса, что обеспечивает повышение экономичности турбоустановки; размещение обоих отопительных отборов в цилиндре среднего давления (ЦСД) даёт возможность при использовании расцепной муфты отключать ЦНД при переходе на теплофикационный режим.

В других трудах на данную тематику [1] изложены основные принципы охлаждения высокотемпературных паровых турбин и конструктивные решения, заложенные при создании первой в мире охлаждаемой паровой турбины СКР-100 (Р-100-300). Паровая турбина СКР-100 (Р-100-300) с параметрами пара $P_{0}=30 \mathrm{MПа}, t_{0}=650{ }^{\circ} \mathrm{C}$ с противодавлением была изготовлена Харьковским турбинным заводом в 1961 году и успешно работала на Каширской ГРЭС до 1979 года, когда была выведена из эксплуатации во вполне рабочем состоянии. Для сравнения приведены некоторые данные об особенностях конструкции и результатах эксплуатации цилиндров сверхвысокого давления паровых турбин американских энергоблоков Philo 6 (изготовитель General Electric) и Eddystone 1 (изготовитель Westinghouse), близких по проектным начальным параметрам пара и времени ввода в эксплуатацию турбины СКР-100. Показанные в эксплуатации высокая надёжность и эффективность системы охлаждения, применённой в цилиндре сверхвысокого давления турбины энергоблока СКР-100, подтверждают правомерность и целесообразность принципов и конструктивных решений, заложенных при её создании. По мере дальнейшего повышения температур рабочего пара реализация предложенного подхода к охлаждению многоступенчатых турбин позволит ограничить применение для крупных турбинных деталей новых более дорогостоящих жаропрочных материалов, необходимых для изготовления паровых котлов, а в некоторых случаях вообще отказаться от их использования.

В научной публикации [5] автор отмечает, что чаще всего на практике придерживаются традиционных правил эксплуатации: чем выше параметры свежего и вторичного пара и чем ниже давление в конденсаторе, тем выше экономичность турбоустановки. В то же время в научнотехнической литературе приводятся достаточно аргументированные доказательства того, что такой подход, особенно при пониженных нагрузках, не всегда корректен. Это относится к регулированию температуры промежуточного перегрева пара $t_{\text {п.п. }}$ В статье автором представлены результа-

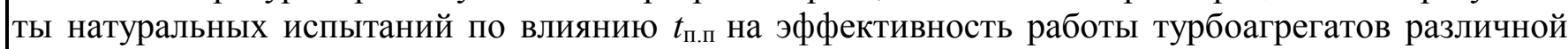

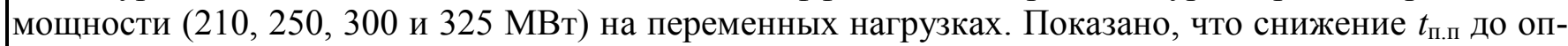
тимального значения на $10 \ldots 30^{\circ} \mathrm{C}$ в зависимости от нагрузки и давления в конденсаторе приводит к повышению тепловой экономичности ПТУ на $1 . .2 \%$.

К следующему из рассматриваемых направлений исследований можно отнести методику математического моделирования. Так, в материалах источника [8] представлена разработка методики математического моделирования пылеугольных конденсационных энергоблоков СКП с системами серо- и азотоочистки и математическая модель их функционирования в энергосистеме. На основе проведённой схемно-параметрической оптимизации разработаны эффективные технологические схемы энергоблоков СКП 330, 500, 660, 800 МВт с системами очистки дымовых газов. Выполнены комплексные технико-экономические исследования энергоблоков СКП 330, 500, 660, 800 МВт, работающих на сибирских углях, и по их результатам автор предлагает рекомендации по выбору рациональных схем и расходно-термодинамических параметров для энергоблоков СКП, конструктивно-компоновочных параметров систем очистки дымовых газов.

В работе [6] проведён анализ объектов исследования и разработано обоснование новых, более совершенных математических моделей и методик переменных режимов работы теплофикационных турбоустановок на основе реальных энергетических характеристик турбинных отсеков и вспомогательного оборудования по результатам обобщения экспериментального материала и данных промышленных испытаний. Усовершенствованы вычислительные методы математического моделирования, а именно методики решения системы нелинейных уравнений большой раз- 
мерности, проведена модернизация существующих алгоритмов и численных методов применительно к расчёту режимов работы теплофикационных турбоустановок. Произведена апробация результатов работы на ряде ТЭЦ и подтверждение эффективности этих результатов экспериментальными данными.

Таким образом, обзор опубликованных в открытой печати работ по вопросу совершенствования и развития мощных паровых турбин на сверхкритические и суперсверхкритические параметры пара показывает, что перспективные турбины должны отличаться сверхвысокими параметрами свежего пара $\left(P_{0}=30 \ldots 35 \mathrm{MПа}, t_{0}=600 \ldots 650^{\circ} \mathrm{C}\right)$, одним или двумя промежуточными перегревами пара до $t_{\text {п.п }}=t_{0}$ или выше, развитой схемой регенеративного подогрева основного конденсата и питательной воды, высокой тепловой экономичностью (КПД конденсационной ТУ $45 \ldots 47$ \%).

\section{ЛИТЕРАТУРА}

1. Аркадьев, Б. А. Особенности охлаждения паровых турбин на примере турбины СКР-100 на суперкритические параметры пара / Б. А. Аркадьев. - М.: Теплоэнергетика, 2015. - 42 с.

2. Валуева, Е. П. Численное исследование теплообмена и турбулентного течения диоксида углерода в трубе при сверхкритическом давлении / Е. П. Валуева, Е. Н. Кулагин. - М.: Теплоэнергетика, 2012. - 41 с.

3. Карилов, В. Ф. Экономическая эффективность использования сверхвысоких значений начальных параметров пара в теплофикационных энергоблоках / В. Ф. Карилов, Е. А. Захаренков. - М.: Теплоэнергетика, 2014. $-3 \mathrm{c}$.

4. Концепция турбин на суперсверхкритические, сверхкритические и докритические параметры пара В. Е. Михайлов, Л. А. Хоменок, И. И. Пичугин [и др.]. - М.: Теплоэнергетика, 2017. - 12 с.

5. Тарелин, А. А. Влияние температуры промежуточного перегрева на эффективность паровых турбоустановок ТЭС, работающих на переменных режимах / А. А. Тарелин. - М.: Теплоэнергетика, 2017. - 71 с.

6. Татаринова, Н. В. Математическое моделирование теплофикационных турбоустановок для решения задач повышения энергетической эффективности работы ТЭЦ: автореф. дис. ... канд. техн. наук: 05.04.12 Татаринова Наталья Владимировна. - Екатеринбург, 2014. - 24 с. - Библиогр.: с. 20-24.

7. Пылеугольные энергоблоки на супер- и ультрасверхкритические параметры пара / А. Г. Тумановский, А. Л. Шварц, Е. В. Сомова [и др.]. - М.: Теплоэнергетика, 2017. - 19 с.

8. Шепель, В. С. Технико-экономическое исследование энергоблоков с суперкритическими параметрами и установками серо- и азотоочистки: автореф. дис. ... канд. техн. наук: 05.14.14 / Шепель Виталий Сергеевич. -Новосибирск, 2013. - 22 с.

9. Технические решения по топочному устройству котла на суперкритические параметры пара А. В. Штегман, И. А. Рыжий, Д. В. Сосин [и др.]. - М.: Теплоэнергетика, 2017. - 30 с. 